Article

\title{
Artemisia Iwayomogi Extract Attenuates High-Fat Diet-Induced Hypertriglyceridemia in Mice: Potential Involvement of the Adiponectin-AMPK Pathway and Very Low Density Lipoprotein Assembly in the Liver
}

\author{
Jinhui Lee ${ }^{1}$, Vikram P. Narayan ${ }^{1}$, Eun Young Hong ${ }^{2}$, Wan Kyunn Whang ${ }^{2}$ and Taesun Park ${ }^{1, *}$ \\ 1 Department of Food and Nutrition, Brain Korea 21 PLUS Project, Yonsei University, 50 Yonsei-ro, \\ Seodaemun-gu, Seoul 03722, Korea; Jinhui9101@naver.com (J.L.); narayan.v.2012@gmail.com (V.P.N.) \\ 2 Pharmaceutical Botany Laboratory, College of Pharmacy, Chung-Ang University, Heukseok-dong, \\ Dongjak-gu, Seoul 06974, Korea; hrosal2001@naver.com (E.Y.H.); whang-wk@cau.ac.kr (W.K.W.) \\ * Correspondence: tspark@yonsei.ac.kr; Tel.: +82-221-233-123; Fax: +82-236-531-18
}

Received: 12 July 2017; Accepted: 11 August 2017; Published: 12 August 2017

\begin{abstract}
This study aimed to examine the protective effect of Artemisia iwayomogi extract (AI) against hypertriglyceridemia induced by a high-fat diet (HFD) in mice and to uncover the underlying molecular mechanisms. C57BL/6N mice were fed chow, HFD, HFD $+0.1 \%$ AI, HFD $+0.25 \%$ AI, or HFD $+0.5 \%$ AI for 10 weeks. The addition of $0.25 \%$ and $0.5 \%$ AI resulted in dose-dependent improvements in the major parameters of hypertriglyceridemia, including plasma triglyceride, free fatty acids, apolipoprotein B, and lipoprotein lipase, with parallel reductions in body weight gain, hepatic lipid accumulation, and insulin resistance. These beneficial effects were accompanied by the activation of adiponectin-adenosine monophosphate-activated protein kinase (AMPK) mediated signaling cascades in the liver, which downregulated molecules involved in lipogenesis and concurrently upregulated molecules related to fatty acid oxidation. The downregulation of molecules involved in very low density lipoprotein assembly, which was associated with improved hepatic insulin signaling, also appeared to contribute to the AI-induced attenuation of hypertriglyceridemia.
\end{abstract}

Keywords: Artemisia iwayomogi; hypertriglyceridemia; adiponectin; lipogenesis; fatty acid oxidation; very low density lipoprotein synthesis

\section{Introduction}

Hypertriglyceridemia refers to a fasting plasma triglyceride (TG) concentration that typically increased above the 95th percentile for age and sex in the population, along with the presence of additional quantitative or qualitative lipoprotein abnormalities [1,2]. The elevated plasma TG concentrations are predominantly seen in disorders characterized by insulin resistance, central obesity, and metabolic syndrome [3] and are considered as an independent risk factor for atherosclerotic cardiovascular disease [4]. Plasma TGs can be obtained from exogenous sources such as dietary fat and are carried in chylomicrons or they can be obtained from endogenous sources such as the liver and are carried in very low density lipoprotein (VLDL) particles. In capillaries within adipose and muscle tissues, these lipoproteins and chylomicrons are hydrolyzed by lipoprotein lipase (LPL) into free fatty acids (FFAs). Experimental animals have been subjected to a high-fat diet (HFD) to induce hypertriglyceridemia with concomitant visceral adiposity, hepatic steatosis, and insulin resistance. The abnormal concentration of TG-rich lipoproteins in the fasting plasma of HFD-fed rodents resulted from upregulated lipogenic and secretory pathways and/or decreased peripheral 
catabolism, which occurred mainly through reduced LPL activity. Additionally, the insulin resistance observed in HFD-fed animals drove the increased flux of FFAs into hepatocytes and stimulated VLDL synthesis and secretion by the liver [5], which contributed to hypertriglyceridemia.

The general treatment regimen for hypertriglyceridemia includes lifestyle changes and dietary modifications. When these have not been successful, drug treatments, including fibrates, omega- 3 fatty acids, and nicotinic acid, alone or in combination with statins, are also used [6]. The potential of natural products to treat hypertriglyceridemia is still largely unexplored and might offer alternative remedies. Artemisia iwayomogi is a perennial aromatic plant with yellow flowers, distributed throughout Korea. The aerial parts of $A$. iwayomogi have been used in oriental medicine for centuries to cure various infectious diseases such as carbuncles, cholecystitis, hepatitis, and jaundice [7,8]. A hepatoprotective effect of $A$. iwayomogi extract was reported in rodent models with different types of liver diseases, such as alcoholic fatty liver [9], carbon tetrachloride-induced chronic hepatic fibrosis [10,11], and cholestatic liver fibrosis [12]. We previously reported that $A$. iwayomogi extract $(0.5 \% w / w$ diet) reduced visceral fat accumulation and obesity-related biomarkers in mice fed a HFD by modulating the expression of genes associated with adipogenesis and inflammation in adipose tissues [13]. Concurrently in this extract-fed mice, we also observed a decrease in plasma TG levels, however the underlying mechanism responsible was not elucidated. A more recent study reported that a mixture $(0.1 \% w / w$ diet $)$ of $A$. iwayomogi and Curcuma longa extracts provoked a synergistic effect in attenuation of hyperlipidemia in HFD-fed mice, but $A$. iwayomogi extract $(0.1 \% w / w$ diet $)$ itself did not affect serum TG levels [12]. In addition to an appropriate dose necessary to reduce plasma TG levels, the differences in extract solvent and methods used in these two studies may also account for the reported variation in A. iwayomogi extract activity. Therefore, our study aimed to examine the protective effects of different doses of $A$. iwayomogi extract against hypertriglyceridemia induced by a HFD in mice and to uncover the molecular mechanisms involved in TG-rich lipoprotein metabolism in the liver.

\section{Results}

\subsection{Chromatographic Analysis of A. iwayomogi Extract (AI)}

The high performance liquid chromatography (HPLC) chromatogram revealed that scopolin (I, $0.97 \pm 0.12 \% w / w$ ), 5-O-caffeoylquinic acid (II, $3.39 \pm 0.34 \% w / w$ ), patuletin-3-O-glucoside (III, $0.50 \pm 0.11 \% w / w)$, scopoletin (IV, $0.84 \pm 0.01 \% w / w)$, 3,5-dicaffeoylquinic acid (V, $5.20 \pm 0.4 \%$ $w / w$ ) and 3,4-dicaffeoylquinic acid (VI, $0.79 \pm 0.02 \% w / w)$ were the major organic components of A. iwayomogi extract (AI) (Figure 1).

(A)

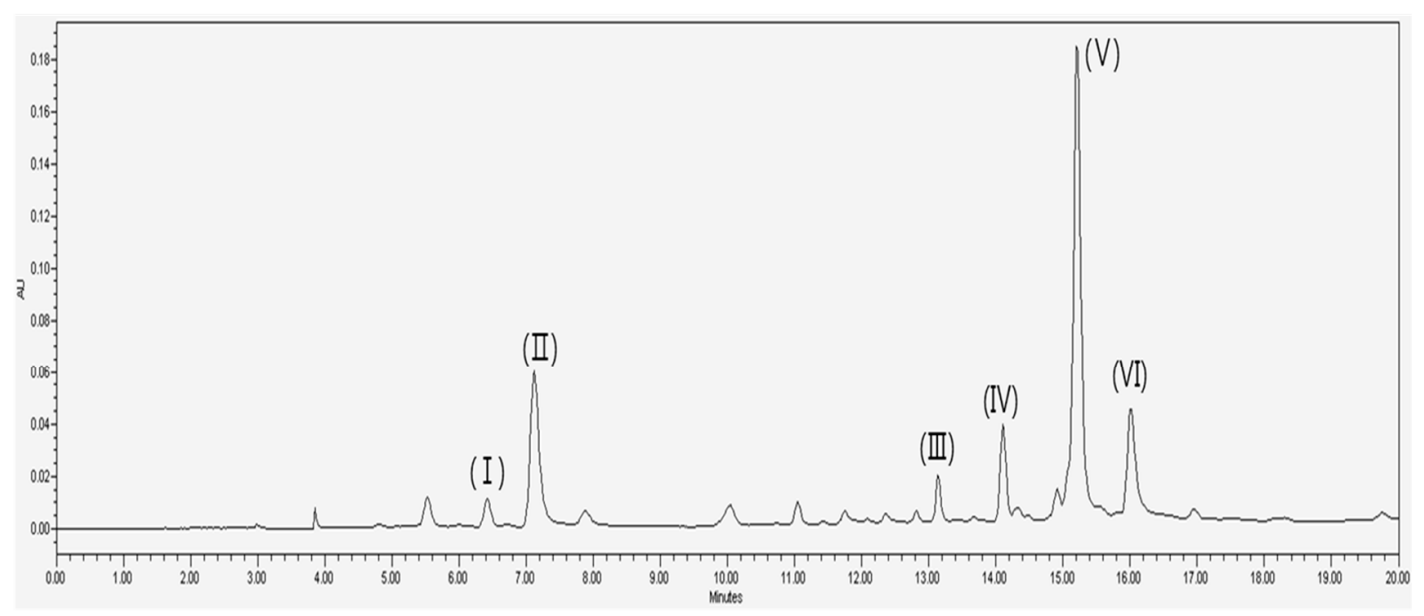

Figure 1. Cont. 
(B)

\begin{tabular}{cclc}
\hline Peak & Molecular structures & Name & $\% w / w$ \\
\hline I & & Scopolin & $0.97 \pm 0.12$ \\
& & & \\
\hline
\end{tabular}

\begin{tabular}{|c|c|c|}
\hline II & 5-O-caffeoylquinic acid & $3.39 \pm 0.34$ \\
\hline III & patuletin-3-O-glucoside & $0.50 \pm 0.11$ \\
\hline IV & scopoletin & $0.84 \pm 0.01$ \\
\hline V & 3,5-dicaffeoylquinic acid & $5.20 \pm 0.4$ \\
\hline VI & 3,4-dicaffeoylquinic acid & $0.79 \pm 0.02$ \\
\hline
\end{tabular}

Figure 1. The contents of the individual bioactives identified in Artemisia iwayomogi extract (AI). (A) A representative high performance liquid chromatography (HPLC) chromatogram of the compound present in the extract is shown. The sample was run three times at $330 \mathrm{~nm}$; (B) the molecular structures and concentrations $(\% w / w)$ of compounds identified in AI.

\subsection{AI Attenuates Hypertriglyceridemia in Mice Fed a High-Fat Diet}

The metabolic actions of AI were evaluated following the administration of the extract by food admixture to C57BL/6N male mice challenged with a HFD. AI administration significantly reduced the body weight of HFD-fed mice in a dose- and time-dependent manners. After 10 weeks of treatment, $0.25 \%$ and $0.5 \%$ AI reduced the HFD-induced weight gain in mice by $24 \%$ and $36 \%$, respectively. Importantly, this effect on body weight gain was not a result of altered feeding behavior (Figure 2A). HFD-induced hypertriglyceridemia was significantly improved in the mice that received $0.25 \%$ and $0.5 \% \mathrm{AI}$; the plasma levels of both TG and total apolipoprotein B (ApoB), the components of VLDL, were reduced. The decreased cholesterol concentration in the plasma of $0.5 \%$ AI-fed mice resulted mainly from a decrease in VLDL + low density lipoprotein (LDL) cholesterol. The plasma levels of free fatty acids and LPL, as determined by enzyme-linked immunosorbent assay (ELISA), were reduced by AI treatment in HFD-fed mice. The AI-induced improvements in lipid profiles appeared dose-dependent and were most significant at the highest dosage tested, $0.5 \%$ (Figure 2B,C). 
(A)

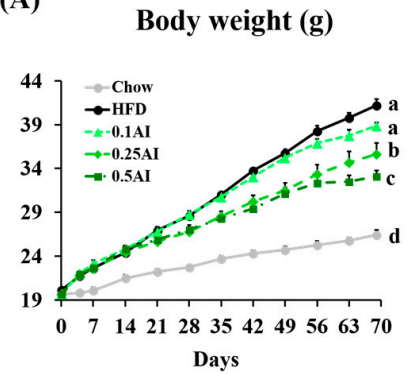

Body weight gain (g/10 weeks)

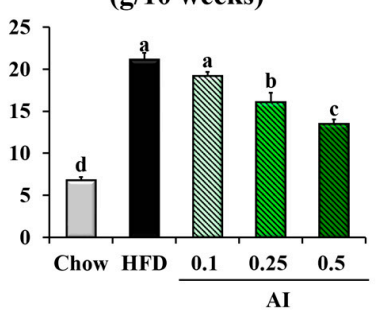

Food intake (kcal/day)

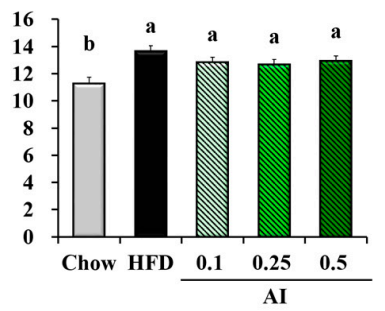

(B)

Triglyceride $(\mathrm{mmol} / \mathrm{L})$
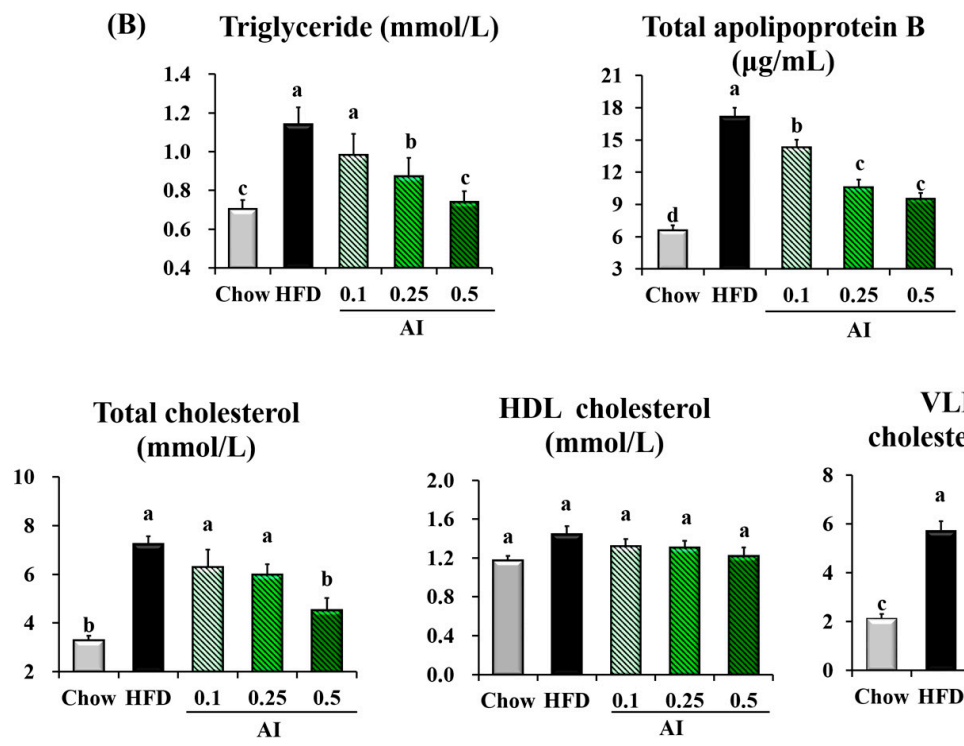

VLDL+LDL cholesterol $(\mathrm{mmol} / \mathrm{L})$

(C) Free fatty acid $(\mu \mathrm{Eq} / \mathrm{L})$
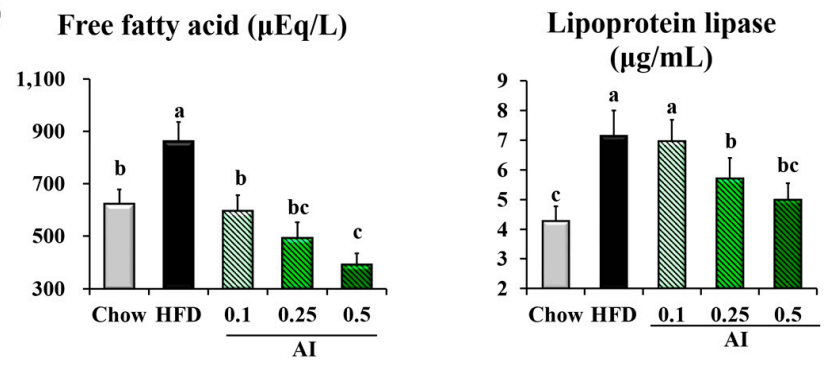

Figure 2. AI attenuates hypertriglyceridemia in high-fat diet (HFD)-fed mice. (A) Changes in body weight and food intake; (B) plasma levels of triglyceride, total apolipoprotein B, total cholesterol, very low density lipoprotein (VLDL) + LDL cholesterol, and high density lipoprotein (HDL) cholesterol; (C) plasma free fatty acid and lipoprotein lipase concentrations. Data are the mean \pm standard error of the mean (SEM) of $n=8$ mice. Statistical analysis was performed using one-way analysis of variance (ANOVA) and analyzed further by Duncan's multiple range test. Different letters above the bars indicate significant differences among experimental groups $(p<0.05)$.

\subsection{AI Alleviates High-Fat Diet-Induced Hepatic Lipid Accumulation}

The 10-weeks HFD significantly increased the size of the liver and lightened the color of the liver. AI supplementation clearly reversed the HFD-induced adverse changes in a dose-dependent manner. The mass of liver tissue from mice fed the HFD supplemented with $0.5 \%$ AI was $30 \%$ lower than those fed the HFD only (Figure 3A). In addition, the reduced liver mass observed in mice that received $0.5 \% \mathrm{AI}$ was associated with a smaller number and size of lipid droplets, a feature that correlated with 
leanness and hepatic steatosis scores (Figure 3B). Although the hepatic inflammation scores followed a pattern similar to that of the steatosis scores, there were no statistically significant difference among the groups. The HFD-induced lipid accumulation in the liver was ameliorated by AI administration, as shown by the dose-dependent reduction of hepatic levels of TG, cholesterol, and FFAs (Figure 3C). Plasma alanine aminotransferase (ALT) and aspartate aminotransferase (AST) activities associated with hepatic injury were markedly increased in HFD-fed mice, but were reduced by AI administration in a dose-dependent manner (Figure 3D).

(A)

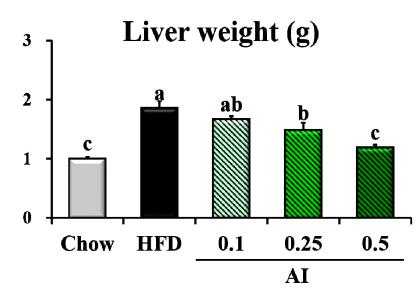

(B)

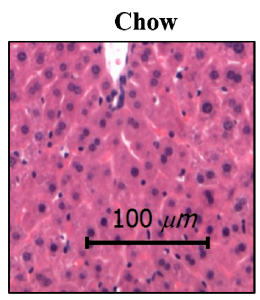

HFD

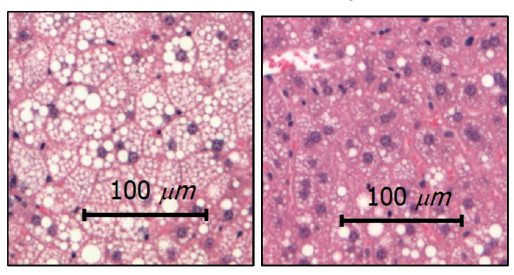

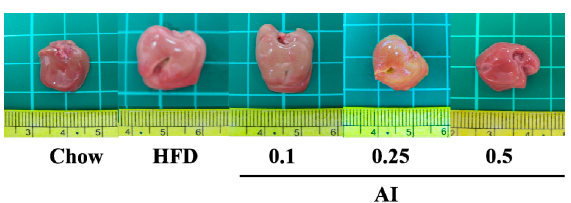
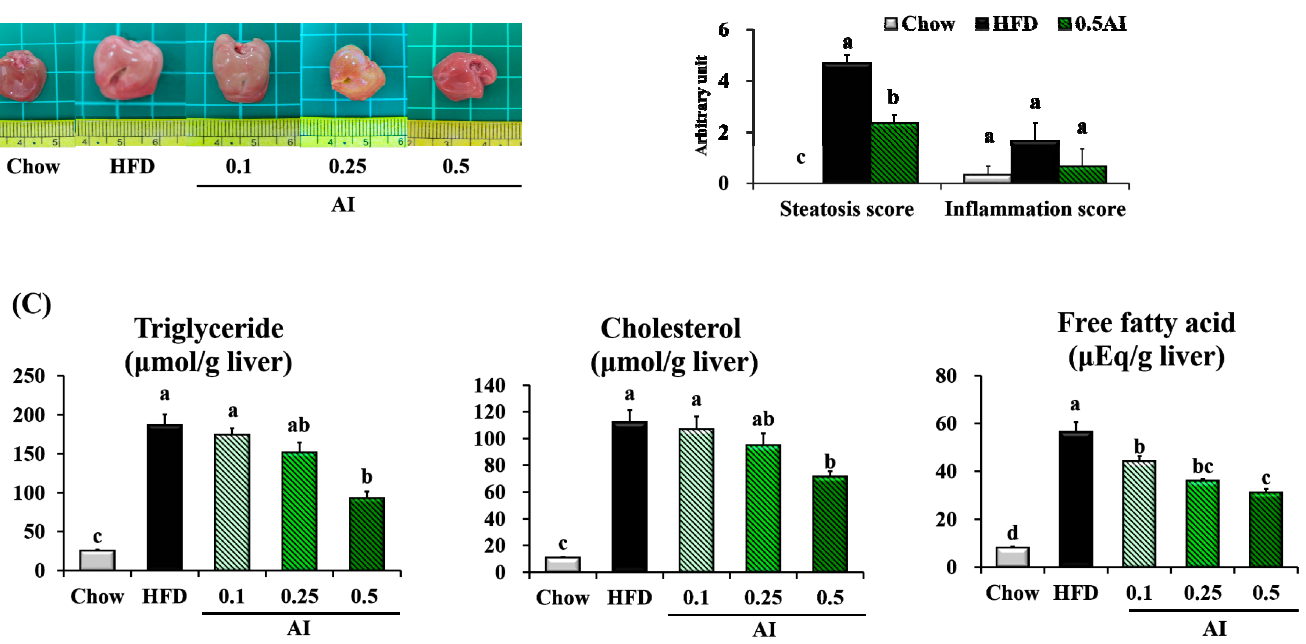

(D)
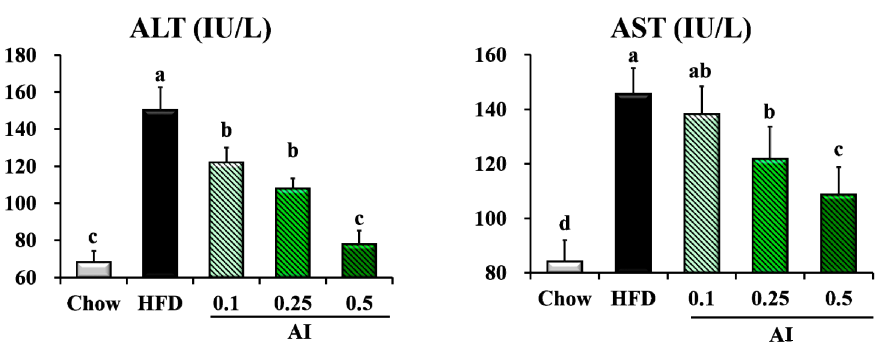

Figure 3. AI alleviates hepatic steatosis in HFD-fed mice. (A) Liver weights and gross morphology; (B) representative images of H\&E-stained sections of liver (scale bar $=100 \mu \mathrm{m}$ ) and scores for hepatic steatosis and inflammation; (C) hepatic levels of triglyceride, cholesterol, and free fatty acid; (D) plasma aminotransferase (ALT) and aspartate aminotransferase (AST) activities; Data are the mean \pm SEM of $n=8$. Statistical analysis was performed using one-way ANOVA and analyzed further by Duncan's multiple range test. Different letters above the bars indicate significant differences among experimental groups $(p<0.05)$.

\subsection{AI Activates Adiponectin-Adenosine Monophosphate-activated Protein Kinase (AMPK) Mediated} Signaling Pathways in the Liver

As plasma adiponectin level was completely elevated by AI administration (Figure 4A) and AMPK is one of the key activators of the fatty acid catabolism responsible for sensing low energy 
levels, we tested whether prolonged AI administration could modulate the adiponectin-AMPK pathways in the liver of HFD-fed mice. Immunoblotting and reverse transcription polymerase chain reaction (RT-PCR) analysis were conducted on the liver tissues of mice fed chow, HFD, and 0.5\% AI-supplemented HFD. In HFD-mice, the observed changes (the downregulation of adiponectin receptor 2 ((AdipoR2) and phospho (p)-AMPK protein levels and the upregulation of p-S6 Kinase 1 (S6K1) protein expression) were completely normalized by the administration of AI (Figure 4B). The expression of lipogenic nuclear transcription factors, such as peroxisome proliferator-activated receptor $\gamma(\operatorname{PPAR} \gamma)$, sterol regulatory element binding protein 1c (SREBP1c), and liver X receptor $\alpha$ $(\mathrm{LXR} \alpha)$, was robustly downregulated in the liver of AI-treated mice compared with the HFD mice. The functional relevance of the AI-induced downregulation was confirmed by the decreased expression of direct target genes, including cluster of differentiation 36 (CD36), liver fatty acid binding protein 1 (FABP), ATP citrate lyase (ACL), acetyl-coenzyme A (CoA) carboxylases (ACC), and fatty acid synthase (FAS) (Figure 4C). Additionally, the supplementation of AI to the HFD had a strong positive impact on the expression of the regulators of hepatic lipolysis, such as hepatic triglyceride lipase (HTGL) and acyl CoA synthetase (ACS), and of the transcription factors involved in fatty acid oxidation and inflammation, such as peroxisome proliferator-activated receptor $\alpha(\operatorname{PPAR} \alpha)$ and peroxisome proliferator-activated receptor- $\gamma$ coactivator $1 \alpha(\mathrm{PGC} 1 \alpha)$, and their target genes including carnitine palmitoyltransferase 1 (CPT1), mitochondrial transcription factor A (TFAM), nuclear respiratory factor 1 (NRF1), tumor necrosis factor $\alpha$ (TNF $\alpha$ ), and interlukin-6 (IL-6) (Figure 4D). The expression of TG synthesis enzymes, such as glycerol-3-phosphate acyltransferase (GPAT), glycerol-3-phosphate dehydrogenase (GPDH), phosphatidate phosphohydrolase (p), and diacylglycerol acyltransferase (DGAT), was significantly downregulated in the liver of AI-treated mice compared with the HFD-fed mice (Figure 4E).

(A)
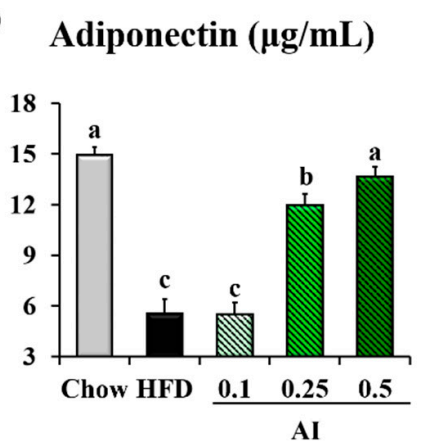

(B)

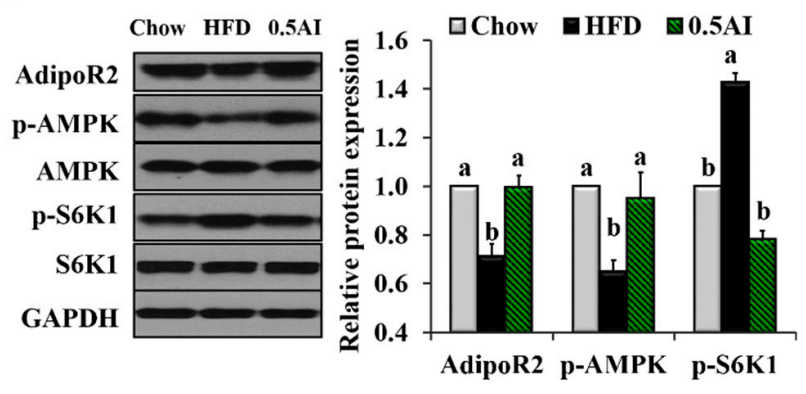

(C)

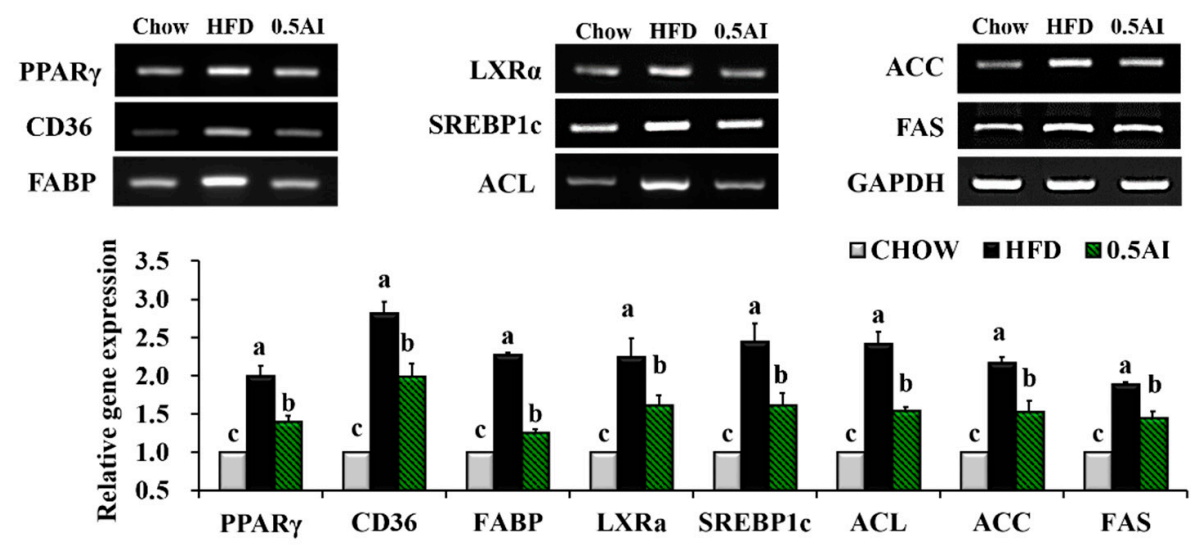

Figure 4. Cont. 
(D)
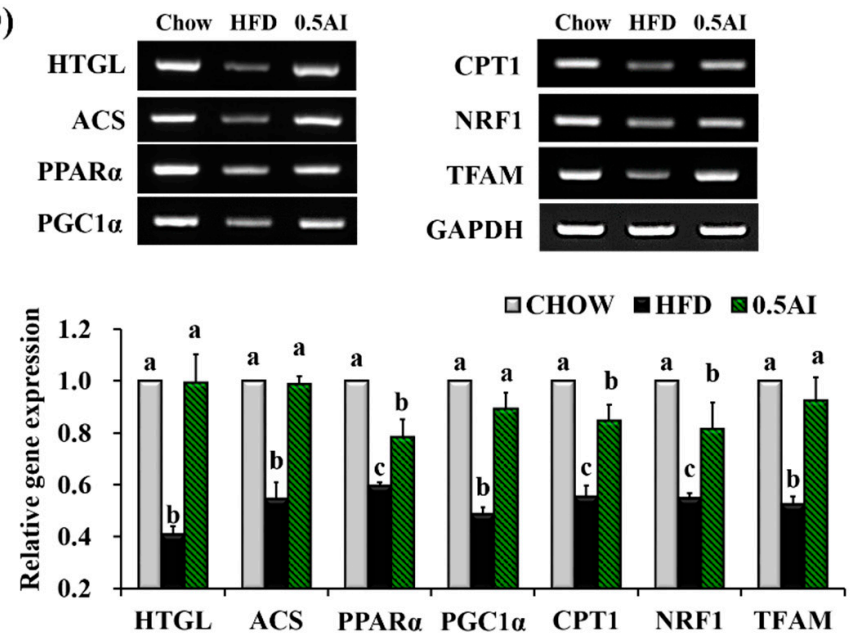

(E)
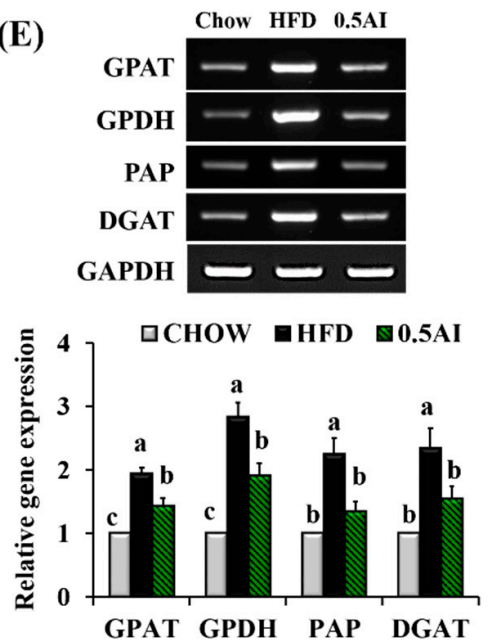

Figure 4. AI activates adiponectin-AMPK mediated signaling pathways in mice. (A) Plasma adiponectin concentrations; (B) representative western blot analysis and quantification of AdipoR2, total adenosine monophosphate-activated protein kinase (AMPK), p-AMPK, total S6K1, and p-S6K1 in the liver; Representative reverse transcription polymerase chain reaction (RT-PCR) product bands and quantitative comparison of mRNA expression for (C) lipogenesis, (D) lipolysis, fatty acid oxidation, inflammation and (E) triglyceride synthesis in the liver. Results are presented as the mean \pm SEM. Statistical analysis was performed using one-way ANOVA and analyzed further by Duncan's multiple range test. Different letters above the bars indicate significant differences among experimental groups $(p<0.05)$.

\subsection{AI Improves Insulin Resistance and Downregulates Molecules Involved in Very Low Density Lipoprotein Assembly}

AI also prevented the negative impact of the HFD on glucose homeostasis; fasting blood glucose and insulin levels were both reduced and the homeostasis model assessment of basal insulin resistance (HOMA-IR) value was decreased (Figure 5A). In addition, mice treated with AI showed improved tolerance to an oral glucose load, as demonstrated by a decreased area under the curve (AUC) value compared with the HFD-fed mice (Figure 5B). As the improved hepatic insulin sensitivity was associated with reduced VLDL assembly from TG and secretion by the liver, we evaluated whether $\mathrm{AI}$ administration could regulate the signaling molecules involved in insulin sensitivity and VLDL assembly in the liver. The downregulation of the phosphorylated form of insulin receptor substrate 1 (IRS1), protein kinase B (AKT), and forkhead box O1 (FOXO) proteins induced by HFD was completely reversed by $\mathrm{AI}$ administration. The protein expression of ApoB100 and gene expression of microsomal triglyceride transfer protein (MTTP), disulfide isomerase (PDI) and apolipoprotein CIII (ApoCIII), which were involved in VLDL packaging, were strongly downregulated in the livers of mice that received AI compared with those of HFD-fed mice (Figure 5C,D). 
(A) $\operatorname{Insulin}(\mathbf{n g} / \mathbf{m L})$

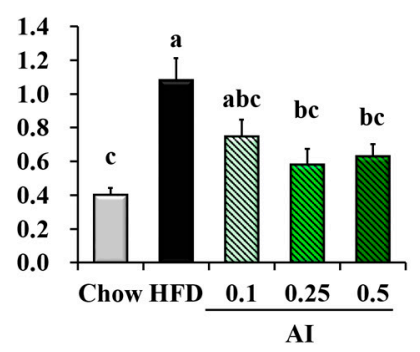

Glucose (mmol/L)

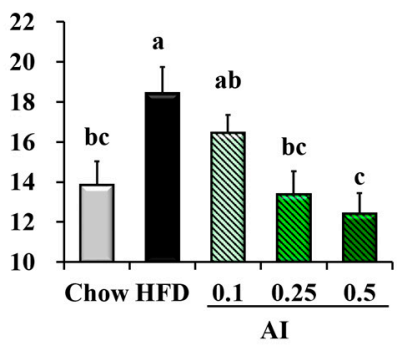

HOMA-IR

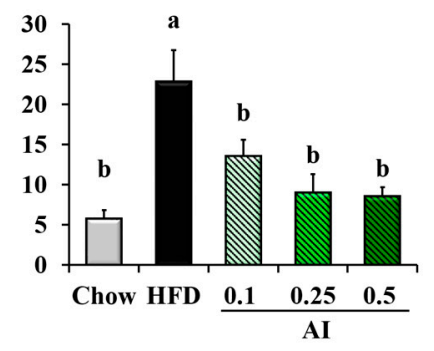

(B)
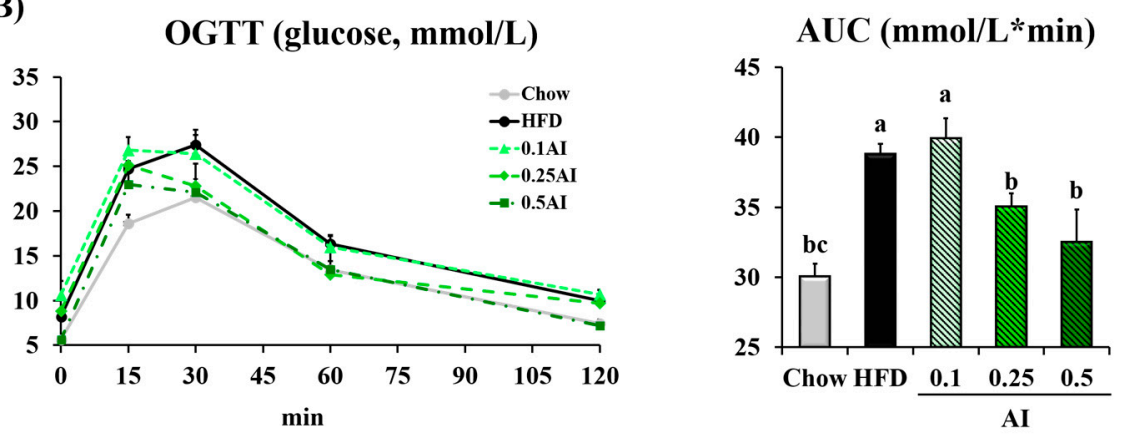

(C)

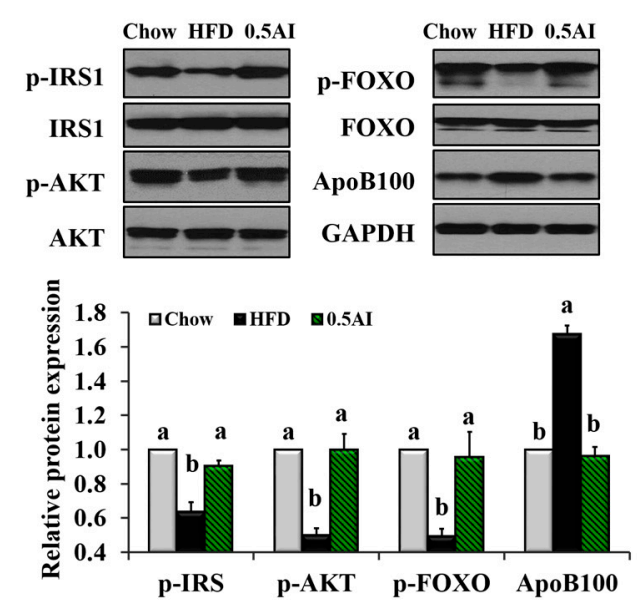

(D)
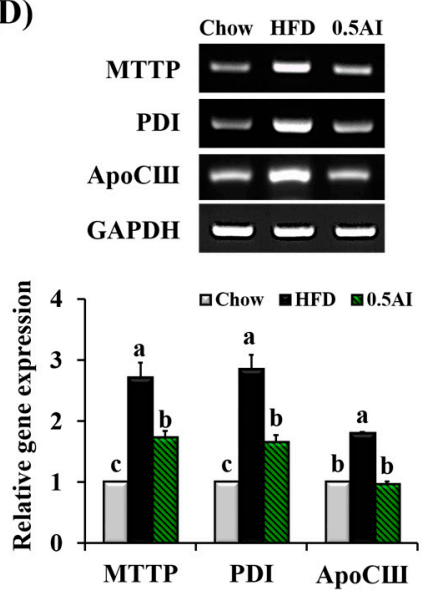

Figure 5. AI improves the hepatic insulin signaling pathway in mice. (A) Fasting plasma levels of insulin and glucose and homeostasis model assessment of basal insulin resistance (HOMA-IR)) index; (B) oral glucose tolerance test (OGTT) and area under the curve (AUC); (C) densitometric quantification of the phosphorylation of IRS1, AKT, FOXO, and ApoB100 in the liver; (D) hepatic expression of genes involved in VLDL assembly; Statistical analysis was performed using one-way ANOVA and analyzed further by Duncan's multiple range test. Different letters above the bars indicate significant differences among experimental groups $(p<0.05)$.

\section{Discussion}

In the present study, the ethanol extract of A. iwayomogi was supplemented to HFD-fed mice. At concentrations of $0.25 \%$ and $0.5 \% \mathrm{AI}$, dose-dependent improvements were observed in the major parameters of hypertriglyceridemia, such as plasma TG, FFA, ApoB, and LPL levels. The supplementation of $0.25 \%$ and $0.5 \% \mathrm{AI}$ (equivalent to 250 and $500 \mathrm{mg} \cdot \mathrm{kg}^{-1}$ body weight of mice/day, respectively) corresponded to intakes of approximately $1.2 \mathrm{~g}$ and $2.4 \mathrm{~g} / 60 \mathrm{~kg}$ adult/day, respectively, when calculated on the basis of normalization to body surface area as recommended by Reagan-Shaw, Nihal, and Ahmad [14] and the US Food and Drug Administration (Available online: https:/ / www.fda. 
gov/downloads/drugs/guidancecomplianceregulatoryinformation/guidances/ucm078932). The toxicological study of AI used in this experiment was conducted in male and female Sprague-Dawley rats after a 13-week repeated oral administration of 500, 1000, or $2000 \mathrm{mg} \cdot \mathrm{kg}^{-1}$ body weight/day and revealed no treatment-related mortality or adverse effects, including clinical observations, motor activity assessment, body weight/weight gain, food consumption, ophthalmoscopy, clinical pathology, hematology, urinalysis, organ weights, gross pathology, or histopathology. Therefore, the no observed adverse effect level (NOAEL) of AI was estimated as equal to or greater than $2000 \mathrm{mg} \cdot \mathrm{kg}^{-1}$ body weight/day in both male and female animals [15]. Similarly, Kim et al. [16] reported the NOAEL for fertility and early embryonic development of $A$. iwayomogi hot water extract as $2000 \mathrm{mg} \cdot \mathrm{kg}^{-1}$ body weight/day for rats.

The HPLC chromatogram of AI revealed the presence of relatively high amounts of specific chlorogenic acids, such as 3,5-dicaffeoylquinic acid $(5.2 \% w / w), 5$-O-caffeoylquinic acid $(3.4 \% w / w)$, and 3,4-dicaffeoylquinic acid $(0.8 \% w / w)$. Chlorogenic acids are a family of esters formed between certain trans-cinnamic acids and (-)-quinic acid and are one of the most abundant polyphenols in the human diet; coffee, fruits, and vegetables are the major sources [17]. Approximately 71 different species of chlorogenic acid have now been identified from different sources [18,19]. Some in vitro and in vivo potential pharmacological properties have been reported, including hypoglycemic, antihypertensive, antiviral, antifungal, hepatoprotective, neuroprotective, and immunoprotective activities [20]. 5-O-Caffeoylquinic acid was reported to prevent mice from diet-induced obesity and obesity related metabolic syndromes, including hepatic steatosis, insulin resistance, and chronic inflammation [21-23]. Other types of chlorogenic acids, such as 3,5-dicaffeoylquinic acid and 3,4-dicaffeoylquinic acid, were also effective for the inhibition of oleic acid-induced lipid accumulation in human hepatoma cell lines (HepG2) [24,25]. Miyamae et al. [26] suggested that caffeoyl groups bound to quinic acid are important for activity and the more caffeoyl groups are bound to quinic acid, the higher accelerating activity on ATP production exhibits.

Besides chlorogenic acids, scopolin $(0.97 \% w / w)$, scopoletin $(0.84 \% w / w)$, and patuletin-3-Oglucoside $(0.50 \% w / w)$ were also present in $\mathrm{AI}$ in considerable amount. Scopoletin and scopolin (a glucoside form of scopoletin) are coumarin compounds which have been identified in many different medicinal plants, including species of Scopolia, Brunfelsia, Solanum, and Mallotus, in addition to Artemisia. [27]. Data from our laboratory have shown that $0.02 \%(w / w)$ scopolin supplemented to HFD mice significantly prevented increments in body weight, and hepatic lipids levels [28]. Scopolin (100 $\mathrm{mg} \cdot \mathrm{kg}^{-1}$ body weight) ameliorated adjuvant-induced arthritis in rats by the downregulation of proinflammatory and proangiogenic cytokines, such as vascular endothelial growth factor, basic fibroblast growth factor-2, and interleukin-6 [29]. Scopoletin $(0.05 \% w / w)$ effectively attenuated alcohol-induced hepatic steatosis in HFD-induced obese mice by the inhibition of lipogenesis through modulation of the AMPK-SREBP1c signaling pathway [30]. The involvement of scopoletin in the protection from the risk of Alzheimer's disease has been suggested as this compound increased extracellular acetylcholine concentration, which is responsible for regulating learning and memory in rat brain. Patuletin-3-O-glucoside is commonly found in A. iwayomogi, but not in other species of Artemisia, such as A. annua and A. capillaries [31-34], and its physiological functions are still unknown. Further studies are needed to gain insight into the contributions of each phenolic compound to the AI-induced attenuation of hypertriglyceridemia in mice.

AMPK is a conserved intracellular energy sensor that has been implicated in the regulation of glucose and lipid homeostasis in hepatocytes [35]. HFD per se reduces circulating adiponectin level, which results in the decreased phosphorylation of AMPK via reduced liver kinase B1 (LKB1) phosphorylation in the liver. The inactivation of AMPK leads to increased phosphorylation and activation of mammalian target of rapamycin (mTOR)/S6K1, a subsequent increase in phosphorylation of LXR $\alpha$ [36], and the ultimate activation of SREBP1c, a lipogenic transcription factor. AMPK is also a well-established cellular energy sensor that switches on catabolic pathways, including fatty acid oxidation, and switches off anabolic pathways, including lipogenesis [37]. The HFD-induced 
inactivation of AMPK negatively regulated fatty acid oxidation through the inactivation of the transcription factors PGC1 $\alpha$ and PPAR $\alpha$ and the downregulation of their target genes, including CPT1, NRF1, and TFAM (Figure 6).

We observed that AI effectively reversed the HFD-induced decreases in plasma adiponectin level and hepatic AMPK phosphorylation in mice. The activation of AMPK following AI administration was accompanied by the inactivation of a downstream signaling cascade through S6K1, LXR $\alpha$, SREBP1c, PPAR $\gamma$, and their target genes involved in lipogenesis (FAS, ACL, ACC, FABP, and CD36), and by the activation of a signaling cascade through PGC1 $\alpha, \operatorname{PPAR} \alpha$, and their target genes (CPT1, NRF1, and TFAM) involved in fatty acid oxidation (Figures 4 and 6). The TG biosynthetic pathway in the liver is catalyzed by several enzymes: GPAT and DGAT catalyze the first and last steps in TG synthesis, respectively. GPDH is the enzyme responsible for the catalysis of the reversible redox conversion of dihydroxyacetone phosphate to glycerol 3-phosphate and phosphatidate phosphohydrolase (PAP) catalyzes the dephosphorylation of phosphatidate, which yields diacylglycerol and inorganic phosphate [38-41]. In the meantime, hepatic TGs are hydrolyzed by HTGL to form FFAs and the carboxyl group of the FFA forms a linkage with the thiol group of CoA to yield a fatty acyl-CoA; this process is catalyzed by ACS. The AI-induced attenuation of hypertriglyceridemia observed in HFD-fed mice was also associated with the downregulation of genes involved in TG biosynthesis (GPAT, GPDH, PAP, and DGAT) (Figure 4E) and the upregulation of genes related to TG hydrolysis (HTGL and ACS) in the liver (Figure 4D).

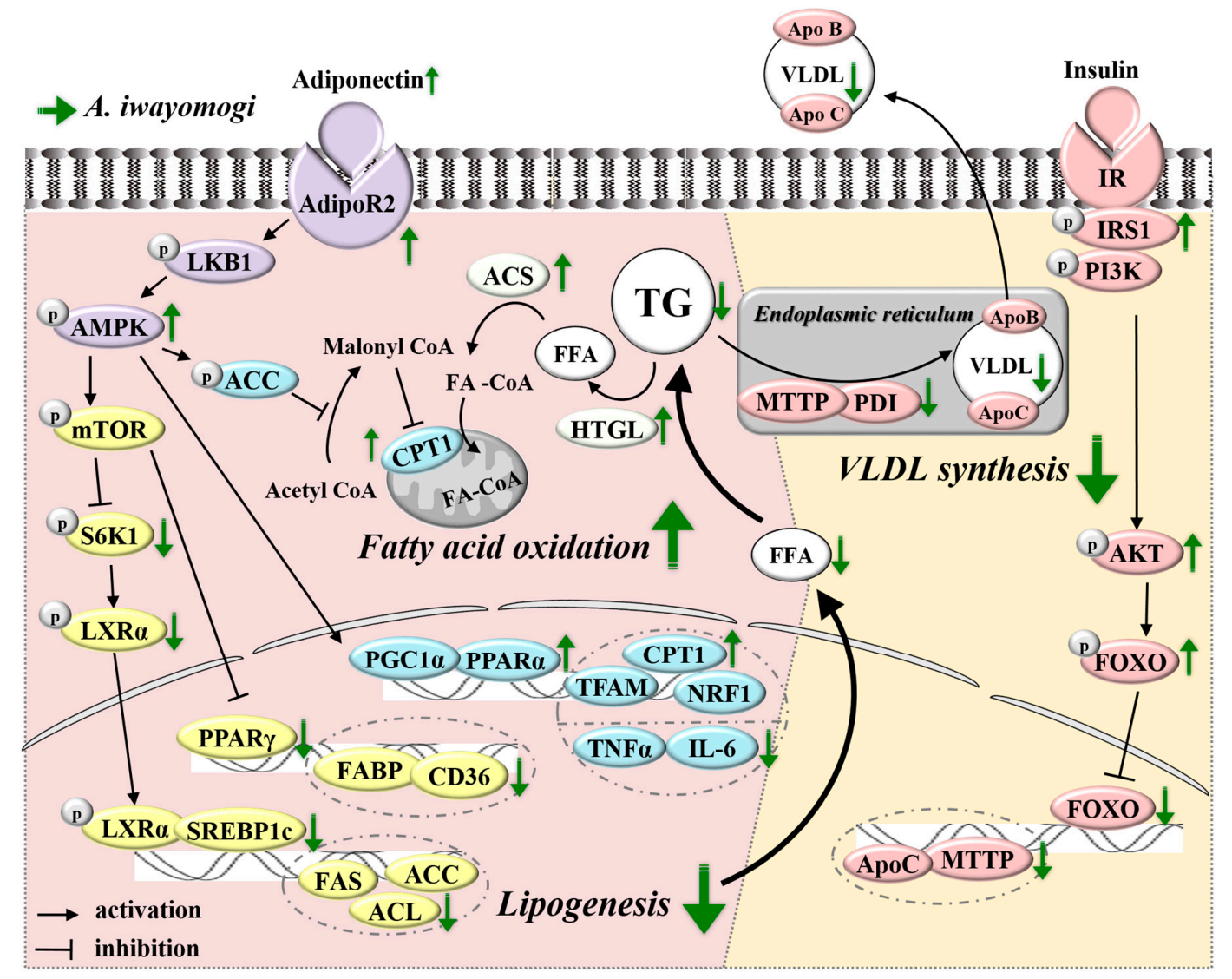

Figure 6. Schematic representation of mechanisms by which AI inhibits HFD-induced hypertriglyceridemia.

VLDL assembly in the liver is dependent on substrate availability and tightly regulated by insulin $[42,43]$. When hetero-dimerized with its small subunit PDI in the endoplasmic reticulum, MTTP catalyzed the transfer of TG to nascent ApoB, the rate-limiting step in hepatic VLDL production [44-46]. Under fasting conditions, hepatic VLDL production is induced, increasing VLDL secretion into the 
blood, whereas in response to postprandial insulin release, hepatic VLDL production is suppressed to limit plasma TG excursion [47-50]. The acute inhibition of VLDL production by insulin is critical for the rapid adaptation of the liver metabolism between fasting and refeeding states to maintaining plasma lipids within the physiological range. However, in an insulin-resistant state, hepatic VLDL production is elevated: the cell surface insulin receptor and intracellular mediators such as IRS1 and AKT are dephosphorylated, leading to decreased phosphorylation and degradation of FOXO and subsequent upregulation of MTTP and ApoC, which are key molecules in the assembly and intracellular trafficking of newly synthesized VLDL (Figure 6). We found that AI efficiently reversed the HFD-induced insulin resistance in mice as the fasting plasma levels of insulin and glucose and the AUC value from oral glucose loading were all significantly decreased. Furthermore, AI administration increased the phosphorylated form of proteins involved in insulin signaling, such as p-IRS1, p-AKT, and p-FOXO, and subsequently suppressed MTTP, PDI, and ApoCIII genes and ApoB100 protein in the liver (Figures 5 and 6). The favorable effects of AI, comprising the improvement of HFD-induced insulin resistance and the downregulation of molecules involved in VLDL assembly in the liver, might be partially reflected in decreased plasma concentrations of triglyceride and ApoB protein (Figure 2B).

\section{Materials and Methods}

\subsection{Preparation of AI and HPLC Analysis}

The dried aerial part of A. iwayomogi was collected from Kyung-Dong Oriental Market in South Korea and identified by Wan Kyunn Whang. A voucher was deposited at the Botany Resources Laboratory at Chung-Ang University (Seoul, Korea). The A. iwayomogi was coarsely powdered and extracted with $50 \%$ ethanol on a rotary shaker at room temperature for $48 \mathrm{~h}$. Liquid extract was separated and extracted with $50 \%$ ethanol at room temperature for additional $24 \mathrm{~h}$. The ethanol extract was filtered with filter paper (Hyundai Micro Co., Seoul, Korea) and concentrated in a vacuum evaporator (N-11, Eyela, Tokyo, Japan). The mixture was sterilized for $10-20 \mathrm{~min}$ at $80-95^{\circ} \mathrm{C}$, dried in a spray dryer (B-290, Buchi, Germany) with maltodextrin.

For the HPLC of AI, the dried ethanol extract of $A$. iwayomogi $(1 \mathrm{mg})$ was immersed in $1 \mathrm{~mL} 50 \%$ aqueous ethanol and filtered through a $0.2-\mu \mathrm{m}$ membrane filter. HPLC analyses were performed using a Waters HPLC system (Waters Corporation, Milford, MA, USA) with an autosampler. Chromatographic separation was achieved using a Sunfire C18 column $(4.6 \mathrm{~mm} \times 250 \mathrm{~mm}, 5 \mu \mathrm{m}$ inner diameter, Waters) at $30{ }^{\circ} \mathrm{C}$ with a flow rate of $0.9 \mathrm{~mL} \cdot \mathrm{min}^{-1}$ and a mobile phase composed of $0.1 \%$ $(v / v)$ aqueous formic acid (A) and acetonitrile (B) using the following gradient elution: $85-84 \% \mathrm{~A}$ from $0-5 \mathrm{~min} ; 84-72 \%$ A from $5-10 \mathrm{~min} ; 72-69 \%$ A from $10-15 \mathrm{~min}$, and $69-40 \%$ A from $15-20 \mathrm{~min}$. The injection volume was $10 \mu \mathrm{L}$ and the detection wavelength was set at $330 \mathrm{~nm}$.

\subsection{Animals and Diets}

Five-week-old male C57BL/6N mice (18-20 g) were obtained from Orient Bio (Gyeonggi-do, Korea) and housed in a pathogen-free facility at Yonsei University (Seoul, Korea) at room temperature with a 12-h light/dark cycle. The study was approved by the Institutional Animal Care and Use Committee of the Yonsei Laboratory Animal Research Center (Permit no. IACUC-A-201402-142-01, 10 February 2014). The animals were allowed an acclimatization period of one week, during which they were fed a commercial diet (Purina Rodent Chow 5001, Nestlé Purina, St. Louis, MO, USA) with ad libitum access to tap water. Thereafter, the mice were divided into five groups ( $n=8$ /group), which were each allocated to one of five experimental diets: chow diet (Chow), high-fat diet (HFD) ( $200 \mathrm{~g}$ fat $\cdot \mathrm{kg}^{-1}$ body weight (170 $\mathrm{g}$ of lard and $30 \mathrm{~g}$ of corn oil) $+1 \%(w / w)$ cholesterol), and HFD supplemented with $0.1 \% \mathrm{AI}, 0.25 \% \mathrm{AI}$, and $0.5 \% \mathrm{AI}$, respectively. The mice were subjected to the experimental diet for 10 weeks, during which time all animals were permitted ad libitum access to the diet and water. Throughout the experimental period, weekly body weight and daily food intake were measured. At the end of the experiment, mice were anaesthetized with $0.15 \mathrm{~mL}$ avertin $(2.5 \%$ in 
tert-amyl alcohol) per $10 \mathrm{~g}$ body weight after a 12-h fast. Blood was drawn from the abdominal aorta into an ethylenediaminetetraacetic acid (EDTA)-coated tube. Plasma was subsequently obtained by centrifuging the blood at $2000 \times g$ for $15 \mathrm{~min}$ at $4{ }^{\circ} \mathrm{C}$. The livers were excised, rinsed with phosphate-buffered saline (PBS), and weighed. A portion of each liver was fixed in $10 \%$ formalin for further analysis. The plasma and liver samples were stored at $-80{ }^{\circ} \mathrm{C}$ until analysis.

The oral glucose tolerance test (OGTT) was performed 2 weeks prior to the end of the experimental period on $6 \mathrm{~h}$-fasted mice. Glucose $\left(2 \mathrm{~g} \mathrm{~kg}^{-1}\right.$ bodyweight) was administered by oral gavage and the blood glucose levels were measured from the tail blood at $0,15,30,60,90$, and $120 \mathrm{~min}$ after administration.

\subsection{Biochemical Analysis}

The plasma levels of TG, FFAs, total cholesterol, high density lipoprotein (HDL)-cholesterol, and glucose were enzymatically determined using commercial kits (Bio-Clinical System, Gyeonggi-do, Korea). Plasma LDL + VLDL cholesterol levels were calculated by subtracting the level of HDL cholesterol from the total cholesterol. Plasma total ApoB and LPL concentrations were measured using the commercially available mouse-specific enzyme-linked immunosorbent assay (ELISA) kits (MyBiosource, San Diego, CA, USA). The plasma concentrations of adiponectin and insulin were measured by using a commercially available mouse ELISA kit (Millipore, Billerica, MA, USA). The HOMA-IR, which was used to assess insulin resistance, was calculated as fasting plasma glucose $x$ fasting plasma insulin/22.5. The plasma activities of AST and ALT were measured using commercial kits (Bio-Clinical System). After homogenization of the liver tissues, the lipids were extracted with chloroform: methanol (2:1) as previously described [51]. The chloroform phases were carefully removed, dried under nitrogen, and re-suspended in ethanol; TG, cholesterol and FFAs were assayed using same kits that were used for quantification in plasma.

\subsection{Histological Examination}

For hematoxylin and eosin (H\&E) staining, formalin-fixed liver was embedded into paraffin and cut into $5 \mu \mathrm{m}$ sections. An observer blinded to the treatment groups assigned steatosis ( $0-5$ scale) and inflammation (0-3 scale) values to H\&E-stained liver sections according to semi-quantitative pathological standards. Briefly, the pathological degree of steatosis was visually scored in five non-contiguous medium-power fields $(\mathrm{MPFs}, \times 100)$ as follows: no steatosis $=0$; minimal steatosis $=1$; slight steatosis $=2$; moderate steatosis $=3$; marked steatosis $=4$; severe steatosis $=5$. In addition, the degree of lobular inflammation was scored as follows: no inflammation foci $=0 ; 1-2$ inflammation foci per $100 \times$ field $=1 ; 3-4$ inflammation foci per $100 \times$ field $=2$; $>4$ inflammation foci per $100 \times$ field $=3$.

\subsection{Semi-Quantitative RT-PCR Analysis}

The total mRNA from liver samples was isolated using TRIzol reagent (Invitrogen, Carlsbad, CA, USA). RT-PCR was performed using a Superscript II kit (Invitrogen). The forward and reverse primer sets for target and internal marker genes are listed in Table S1 and the RT-PCR conditions were as follows: initial denaturation, $5 \mathrm{~min}, 94^{\circ} \mathrm{C}$; followed by 35-38 cycles of denaturation, $30 \mathrm{~s}, 94{ }^{\circ} \mathrm{C}$; annealing, $30 \mathrm{~s}, 55^{\circ} \mathrm{C}$; and extension, $1 \mathrm{~min}, 72^{\circ} \mathrm{C}$; with a final extension period of $10 \mathrm{~min}$ at $72{ }^{\circ} \mathrm{C}$. Next, $4 \mu \mathrm{L}$ of each PCR reaction mixture was mixed with $1 \mu \mathrm{L} 6 \times$ loading buffer and loaded onto a $2 \%$ agarose gel containing ethidium bromide. Glyceraldehyde-3-phosphate dehydrogenase (GAPDH) mRNA levels were used as an internal control.

\subsection{Western Blot Analysis}

The liver tissues were lysed in Western lysis buffer consisting of $100 \mathrm{mM}$ Tris- $\mathrm{HCl}$ (pH 7.4), $5 \mathrm{mM}$ EDTA, $50 \mathrm{mM} \mathrm{NaCl}, 50 \mathrm{mM}$ sodium pyrophosphate, $50 \mathrm{mM} \mathrm{NaF}, 100 \mathrm{mM}$ orthovanadate, $1 \%$ Triton $\mathrm{X}-100,1 \mathrm{mM}$ phenylmethylsulfonyl fluoride, $2 \mu \mathrm{g} \cdot \mathrm{mL}^{-1}$ aprotinin, $1 \mu \mathrm{g} \cdot \mathrm{mL}^{-1}$ pepstatin A, and $1 \mu \mathrm{g} \cdot \mathrm{mL}^{-1}$ leupeptin. The samples were frequently vortexed during a 10 -minute incubation 
period on ice and centrifuged for $20 \mathrm{~min}$ at $1300 \times \mathrm{g}$. The protein concentration of each supernatant was quantified using a protein assay reagent from the Bradford assay (Bio-Rad, Richmond, CA, USA) in accordance with the manufacturer's instructions.

The proteins were loaded onto an $8 \%$ sodium dodecyl sulfate polyacrylamide gel electrophoresis (SDS-PAGE), and transferred to a nitrocellulose membrane (Amersham, Buckinghamshire, UK). After transfer, the membranes were blocked with $5 \%$ bovine serum albumin in Tris-buffered saline with $0.05 \%$ Tween 20 and probed with the specified primary antibodies (1:1000 dilution) overnight at $4{ }^{\circ} \mathrm{C}$. Primary antibodies to the following proteins were tested: GAPDH, AMPK, p-AMPK (Thr172), S6K1, p-S6K1 (Thr389), IRS1, p-IRS1 (Ser302), AKT, p-AKT (Ser473), FOXO, p-FOXO (Ser253) (all obtained from Cell Signaling Technology, Danvers, MA, USA), AdipoR2, and ApoB100 (obtained from Abcam, Cambridge, UK). The membranes were washed and incubated with the appropriate secondary antibodies in Tris-buffered saline with $0.05 \%$ Tween 20 for $1 \mathrm{~h}$. The blots were developed using an enhanced chemiluminescence detection kit (Amersham) in accordance with the manufacturer's instructions.

\subsection{Statistical Analysis}

The results of body weight gain and plasma biochemistry are presented as the mean \pm standard error of mean (SEM) of eight mice in each group. The RT-PCR and western blot data are shown as the mean \pm SEM of three independent experiments ( $n=2$ or 3 per experiment) for each group, cumulatively including eight mice. Statistical analysis was performed using one-way ANOVA and analyzed further by Duncan's multiple range test. Differences among experimental groups were considered to be statistically significant for values of $p<0.05$.

\section{Conclusions}

Overall, our observations confirmed that AI improved hypertriglyceridemia, body weight gain, hepatic lipid accumulation, and insulin resistance during the administration of HFD in mice. The AI-induced improvement of hypertriglyceridemia appears to be exerted at two different levels: first, by decreasing lipid availability through stimulation of adiponectin-AMPK mediated signaling cascades; and second, by downregulating molecules involved in TG-rich lipoprotein assembly through improved hepatic insulin resistance. Thus, these findings supported the development of AI as a therapy or prevention for diet-induced hypertriglyceridemia.

Supplementary Materials: Supplementary materials can be found at www.mdpi.com/1422-0067/18/8/1762/s1.

Acknowledgments: This research was supported by the Technology Commercialization Support Program (Program no. 1130373), Ministry of Agriculture, Food and Rural Affairs, and the National Research Foundation of Korea Grant funded by the Korea Government (NRF-2016R1A2B4016189).

Author Contributions: Jinhui Lee, Vikram P. Narayan, and Taesun Park designed the experiments, researched and analyzed data, and wrote the manuscript. Eun Young Hong and Wan Kyunn Whang contributed to acquisition and interpretation of data and reviewed and edited the manuscript.

Conflicts of Interest: The authors declare no conflict of interest.

\section{Abbreviations}

$\begin{array}{ll}\text { ACC } & \text { Acetyl-CoA carboxylases } \\ \text { ACL } & \text { ATP citrate lyase } \\ \text { ACS } & \text { Acyl coa synthetase } \\ \text { AdipoR2 } & \text { Adiponectin receptor } 2 \\ \text { AI } & \text { Artemisia iwayomogi extract } \\ \text { AKT } & \text { Protein kinase B } \\ \text { ALT } & \text { Alanine aminotransferase } \\ \text { AMP } & \text { Adenosine monophosphate } \\ \text { AMPK } & \text { Adenosine monophosphate-activated protein kinase }\end{array}$




\begin{tabular}{|c|c|}
\hline ANOVA & Analysis of variance \\
\hline ApoB & Apolipoprotein B \\
\hline ApoC & Apolipoprotein C \\
\hline AST & Aspartate aminotransferase \\
\hline AUC & Area under the curve \\
\hline CD36 & Cluster of differentiation 36 \\
\hline $\mathrm{CoA}$ & Coenzyme A \\
\hline CPT1 & Carnitine palmitoyltransferase 1 \\
\hline DGAT & Diacylglycerol acyltransferase \\
\hline ELISA & Enzyme-linked immunosorbent assay \\
\hline FABP & Liver fatty acid binding protein 1 \\
\hline FAS & Fatty acid synthase \\
\hline FOXO & Forkhead box O1 \\
\hline GAPDH & Glyceraldehyde-3-phosphate dehydrogenase \\
\hline GPAT & Glycerol-3-phosphate acyltransferase \\
\hline GPDH & Glycerol-3-phosphate dehydrogenase \\
\hline HDL & High density lipoprotein \\
\hline HFD & High-fat diet \\
\hline HPLC & High performance liquid chromatography \\
\hline HOMA-IR & Homeostasis model assessment of basal insulin resistance \\
\hline HTGL & Hepatic triglyceride lipase \\
\hline IL-6 & Interlukin-6 \\
\hline IRS1 & Insulin receptor substrate 1 \\
\hline LDL & Low density lipoprotein \\
\hline LKB1 & Liver kinase B1 \\
\hline LPL & Lipoprotein lipase \\
\hline $\mathrm{LXR} \alpha$ & Liver $X$ receptor $\alpha$ \\
\hline MTTP & Microsomal triglyceride transfer protein \\
\hline NOAEL & No observed adverse effect level \\
\hline NRF1 & Nuclear respiratory factor 1 \\
\hline $\mathrm{p}$ & phospho- \\
\hline PAP & Phosphatidate phosphohydrolase \\
\hline PDI & Protein disulfide isomerase \\
\hline PGC1 $\alpha$ & Peroxisome proliferator-activated receptor- $\gamma$ coactivator $1 \alpha$ \\
\hline $\operatorname{PPAR} \alpha$ & Peroxisome proliferator-activated receptor $\alpha$ \\
\hline PPAR $\gamma$ & Peroxisome proliferator-activated receptor $\gamma$ \\
\hline RT-PCR & Reverse transcription polymerase chain reaction \\
\hline S6K1 & S6 kinase 1 \\
\hline SDS-PAGE & Sodium dodecyl sulfate polyacrylamide gel electrophoresis \\
\hline SEM & Standard error of the mean \\
\hline SREBP1c & Sterol regulatory element binding protein $1 \mathrm{c}$ \\
\hline TFAM & Mitochondrial transcription factor A \\
\hline TG & Triglyceride \\
\hline $\mathrm{TNF} \alpha$ & Tumor necrosis factor $\alpha$ \\
\hline VLDL & Very low density lipoprotein \\
\hline
\end{tabular}

\section{References}

1. Hegele, R.A. Monogenic dyslipidemias: Window on determinants of plasma lipoprotein metabolism. Am. J. Hum. Genet. 2001, 69, 1161-1177. [CrossRef] [PubMed]

2. Hodis, H.N.; Mack, W.J.; Krauss, R.M.; Alaupovic, P. Pathophysiology of triglyceride-rich lipoproteins in atherothrombosis: Clinical aspects. Clin. Cardiol. 1999, 22, 15-20. [CrossRef]

3. Rizzo, M.; Berneis, K. Lipid triad or atherogenic lipoprotein phenotype: A role in cardiovascular prevention? J. Atheroscler. Thromb. 2005, 12, 237-239. [CrossRef] [PubMed] 
4. Hokanson, J.E. Hypertriglyceridemia and risk of coronary heart disease. Curr. Cardiol. Rep. 2002, 4, 488-493. [CrossRef] [PubMed]

5. Tchernof, A.; Despres, J.P. Pathophysiology of human visceral obesity: An update. Physiol. Rev. 2013, 93, 359-404. [CrossRef] [PubMed]

6. Sahebkar, A.; Chew, G.T.; Watts, G.F. Recent advances in pharmacotherapy for hypertriglyceridemia. Prog. Lipid Res. 2014, 56, 47-66. [CrossRef] [PubMed]

7. Kim, J. Illustrated Natural Drugs Encyclopedia; Namsadang Publishers: Seoul, Korea, 1989; p. 249.

8. Park, J. Korean Folk Medicine; Busan National University Publisher: Busan, Korea, 1999; pp. 184-185.

9. Cho, K.; Park, S.-H.; Cha, A.; Park, T. Protective effect of artemisia iwayomogi water extract against alcoholic fatty liver. J. Clin. Biochem. Nutr. 2008, 43, 303-306.

10. Wang, J.H.; Choi, M.K.; Shin, J.W.; Hwang, S.Y.; Son, C.G. Antifibrotic effects of Artemisia capillaris and artemisia iwayomogi in a carbon tetrachloride-induced chronic hepatic fibrosis animal model. J. Ethnopharmacol. 2012, 140, 179-185. [CrossRef] [PubMed]

11. Park, E.J.; Nan, J.X.; Kim, J.Y.; Kang, H.C.; Choi, J.H.; Lee, S.J.; Lee, B.H.; Kim, S.J.; Lee, J.H.; Kim, Y.C.; et al. The ethanol-soluble part of a hot-water extract from artemisia iwayomogi inhibits liver fibrosis induced by carbon tetrachloride in rats. J. Pharm. Pharmacol. 2000, 52, 875-881. [CrossRef] [PubMed]

12. Han, J.M.; Kim, H.G.; Choi, M.K.; Lee, J.S.; Park, H.J.; Wang, J.H.; Lee, J.S.; Son, S.W.; Hwang, S.Y.; Son, C.G. Aqueous extract of artemisia iwayomogi kitamura attenuates cholestatic liver fibrosis in a rat model of bile duct ligation. Food. Chem. Toxicol. 2012, 50, 3505-3513. [CrossRef] [PubMed]

13. Choi, Y.; Yanagawa, Y.; Kim, S.; Whang, W.K.; Park, T. Artemisia iwayomogi extract attenuates high-fat diet-induced obesity by decreasing the expression of genes associated with adipogenesis in mice. eCAM 2013, 2013, 915953. [CrossRef] [PubMed]

14. Reagan-Shaw, S.; Nihal, M.; Ahmad, N. Dose translation from animal to human studies revisited. FASEB J. 2008, 22, 659-661. [CrossRef] [PubMed]

15. Kim, J. A thirteen week repeated oral dose toxicity test and a four week recovery test of artemisia iwayomogi extract in sprague-dawley rats; Dong A Pharmaceutical Company, 2015. Unpublished raw data.

16. Kim, C.-D.; Kim, S.-M.; Im, M.-H.; Lee, J.-H.; Park, J.-H. A study on the reproductive toxicity of artemisia iwayomogi kitamura. Korean J. Herbol. 2003, 18, 157-173.

17. Liang, N.; Kitts, D.D. Role of chlorogenic acids in controlling oxidative and inflammatory stress conditions. Nutrients 2015, 8, 16. [CrossRef] [PubMed]

18. Kweon, M.H.; Hwang, H.J.; Sung, H.C. Identification and antioxidant activity of novel chlorogenic acid derivatives from bamboo (Phyllostachys edulis). J. Agric. Food Chem. 2001, 49, 4646-4655. [CrossRef] [PubMed]

19. Jaiswal, R.; Patras, M.A.; Eravuchira, P.J.; Kuhnert, N. Profile and characterization of the chlorogenic acids in green robusta coffee beans by LC-MS(n): Identification of seven new classes of compounds. J. Agric. Food Chem. 2010, 58, 8722-8737. [CrossRef] [PubMed]

20. Upadhyay, R.; Mohan Rao, L.J. An outlook on chlorogenic acids-occurrence, chemistry, technology, and biological activities. Crit. Rev. Food Sci. Nutr. 2013, 53, 968-984. [CrossRef] [PubMed]

21. Ma, Y.; Gao, M.; Liu, D. Chlorogenic acid improves high fat diet-induced hepatic steatosis and insulin resistance in mice. Pharm. Res. 2015, 32, 1200-1209. [CrossRef] [PubMed]

22. Cho, A.S.; Jeon, S.M.; Kim, M.J.; Yeo, J.; Seo, K.I.; Choi, M.S.; Lee, M.K. Chlorogenic acid exhibits anti-obesity property and improves lipid metabolism in high-fat diet-induced-obese mice. Food Chem. Toxicol. 2010, 48, 937-943. [CrossRef] [PubMed]

23. Shimoda, H.; Seki, E.; Aitani, M. Inhibitory effect of green coffee bean extract on fat accumulation and body weight gain in mice. BMC. Complement. Altern. Med. 2006, 6, 9. [CrossRef] [PubMed]

24. Kim, M.; Park, Y.G.; Lee, H.-J.; Lim, S.J.; Ahn, H.R.; Jung, S.H.; Nho, C.W. Youngia denticulata attenuates diet-induced obesity-related metabolic dysfunctions by activating amp-activated protein kinase and regulating lipid metabolism. J. Funct. Foods. 2015, 18, 714-726. [CrossRef]

25. Randy, A.; Kim, M.; Nho, C.W. Ligularia fischeri and its constituent 3,4-dicaffeoylquinic acid improve obesity-induced nonalcoholic fatty liver disease by regulating lipid metabolism and activating AMPK. J. Funct. Foods 2016, 27, 1-16. [CrossRef]

26. Miyamae, Y.; Kurisu, M.; Han, J.; Isoda, H.; Shigemori, H. Structure activity relationship of caffeoylquinic acids on the accelerating activity on ATP production. Chem. Pharm. Bull. 2011, 59, 502-507. [CrossRef] 
27. Rollinger, J.M.; Hornick, A.; Langer, T.; Stuppner, H.; Prast, H. Acetylcholinesterase inhibitory activity of scopolin and scopoletin discovered by virtual screening of natural products. J. Med. Chem. 2004, 47, 6248-6254. [CrossRef] [PubMed]

28. Yoo, A.; Narayan, V.P.; Hong, E.Y.; Whang, W.K.; Park, T. Scopolin ameliorates high-fat diet induced hepatic steatosis in mice: Potential involvement of sirt1-mediated signaling cascades in the liver. Sci. Rep. 2017, 7, 2251. [CrossRef] [PubMed]

29. Pan, R.; Dai, Y.; Gao, X.; Xia, Y. Scopolin isolated from erycibe obtusifolia benth stems suppresses adjuvant-induced rat arthritis by inhibiting inflammation and angiogenesis. Int. Immunopharmacol. 2009, 9, 859-869. [CrossRef] [PubMed]

30. Lee, H.I.; Yun, K.W.; Seo, K.I.; Kim, M.J.; Lee, M.K. Scopoletin prevents alcohol-induced hepatic lipid accumulation by modulating the AMPK-SREBP pathway in diet-induced obese mice. Metabolism 2014, 63, 593-601. [CrossRef] [PubMed]

31. Zhao, Y.; Geng, C.A.; Ma, Y.B.; Huang, X.Y.; Chen, H.; Cao, T.W.; He, K.; Wang, H.; Zhang, X.M.; Chen, J.J. UFLC/MS-IT-TOF guided isolation of anti-HBV active chlorogenic acid analogues from Artemisia capillaris as a traditional Chinese herb for the treatment of hepatitis. J. Ethnopharmacol. 2014, 156, 147-154. [CrossRef] [PubMed]

32. Park, K.M.; Li, Y.; Kim, B.; Zhang, H.; Hwangbo, K.; Piao, D.G.; Chi, M.J.; Woo, M.H.; Choi, J.S.; Lee, J.H.; et al. High-performance liquid chromatographic analysis for quantitation of marker compounds of Artemisia capillaris thunb. Arch. Pharm. Res. 2012, 35, 2153-2162. [CrossRef] [PubMed]

33. Weathers, P.J.; Towler, M.J. Changes in key constituents of clonally propagated Artemisia annua L. During preparation of compressed leaf tablets for possible therapeutic use. Ind. Crops Prod. 2014, 62, 173-178. [CrossRef] [PubMed]

34. Ferreira, J.F.; Luthria, D.L.; Sasaki, T.; Heyerick, A. Flavonoids from Artemisia annua L. as antioxidants and their potential synergism with artemisinin against malaria and cancer. Molecules 2010, 15, 3135-3170. [CrossRef] [PubMed]

35. Wang, S.; Li, X.; Guo, H.; Yuan, Z.; Wang, T.; Zhang, L.; Jiang, Z. Emodin alleviates hepatic steatosis by inhibiting sterol regulatory element binding protein 1 activity by way of the calcium/calmodulin-dependent kinase kinase-AMP-activated protein kinase-mechanistic target of rapamycin-p70 ribosomal S6 kinase signaling pathway. Hepatol. Res. 2017, 47, 683-701.

36. Hwahng, S.H.; Ki, S.H.; Bae, E.J.; Kim, H.E.; Kim, S.G. Role of adenosine monophosphate-activated protein kinase-p70 ribosomal S6 kinase-1 pathway in repression of liver $X$ receptor- $\alpha$-dependent lipogenic gene induction and hepatic steatosis by a novel class of dithiolethiones. Hepatology 2009, 49, 1913-1925. [CrossRef] [PubMed]

37. Zhang, M.; Wang, C.; Wang, C.; Zhao, H.; Zhao, C.; Chen, Y.; Wang, Y.; McClain, C.; Feng, W. Enhanced AMPK phosphorylation contributes to the beneficial effects of lactobacillus rhamnosus GG supernatant on chronic-alcohol-induced fatty liver disease. J. Nutr. Biochem. 2015, 26, 337-344. [CrossRef] [PubMed]

38. Watt, M.J. Storing up trouble: Does accumulation of intramyocellular triglyceride protect skeletal muscle from insulin resistance? Clin. Exp. Pharmacol. Physiol. 2009, 36, 5-11. [CrossRef] [PubMed]

39. Sato, T.; Morita, A.; Mori, N.; Miura, S. The role of glycerol-3-phosphate dehydrogenase 1 in the progression of fatty liver after acute ethanol administration in mice. Biochem. Biophys. Res. Commun. 2014, 444, 525-530. [CrossRef] [PubMed]

40. Ou, X.; Ji, C.; Han, X.; Zhao, X.; Li, X.; Mao, Y.; Wong, L.L.; Bartlam, M.; Rao, Z. Crystal structures of human glycerol 3-phosphate dehydrogenase 1 (GPD1). J. Mol. Biol. 2006, 357, 858-869. [CrossRef] [PubMed]

41. Smith, S.W.; Weiss, S.B.; Kennedy, E.P. The enzymatic dephosphorylation of phosphatidic acids. J. Biol. Chem. 1957, 228, 915-922. [PubMed]

42. Lewis, G.F.; Uffelman, K.D.; Szeto, L.W.; Weller, B.; Steiner, G. Interaction between free fatty acids and insulin in the acute control of very low density lipoprotein production in humans. J. Clin. Investig. 1995, 95, 158-166. [CrossRef] [PubMed]

43. Den Boer, M.A.; Voshol, P.J.; Kuipers, F.; Romijn, J.A.; Havekes, L.M. Hepatic glucose production is more sensitive to insulin-mediated inhibition than hepatic VLDL-triglyceride production. Am. J. Physiol. Endocrinol. Metab. 2006, 291, E1360-E1364. [CrossRef] [PubMed] 
44. Tietge, U.J.; Bakillah, A.; Maugeais, C.; Tsukamoto, K.; Hussain, M.; Rader, D.J. Hepatic overexpression of microsomal triglyceride transfer protein (MTP) results in increased in vivo secretion of VLDL triglycerides and apolipoprotein B. J. Lipid Res. 1999, 40, 2134-2139. [PubMed]

45. Jamil, H.; Chu, C.H.; Dickson, J.K., Jr.; Chen, Y.; Yan, M.; Biller, S.A.; Gregg, R.E.; Wetterau, J.R.; Gordon, D.A. Evidence that microsomal triglyceride transfer protein is limiting in the production of apolipoprotein B-containing lipoproteins in hepatic cells. J. Lipid Res. 1998, 39, 1448-1454. [PubMed]

46. Hussain, M.M.; Shi, J.; Dreizen, P. Microsomal triglyceride transfer protein and its role in ApoB-lipoprotein assembly. J. Lipid Res. 2003, 44, 22-32. [CrossRef] [PubMed]

47. Malmstrom, R.; Packard, C.J.; Caslake, M.; Bedford, D.; Stewart, P.; Yki-Jarvinen, H.; Shepherd, J.; Taskinen, M.R. Effects of insulin and acipimox on VLDL1 and VLDL2 apolipoprotein B production in normal subjects. Diabetes 1998, 47, 779-787. [CrossRef] [PubMed]

48. Malmstrom, R.; Packard, C.J.; Watson, T.D.; Rannikko, S.; Caslake, M.; Bedford, D.; Stewart, P.; Yki-Jarvinen, H.; Shepherd, J.; Taskinen, M.R. Metabolic basis of hypotriglyceridemic effects of insulin in normal men. Arterioscler. Thromb. Vasc. Biol. 1997, 17, 1454-1464. [CrossRef] [PubMed]

49. Lewis, G.F.; Steiner, G. Acute effects of insulin in the control of VLDL production in humans: Implications for the insulin-resistant state. Diabetes Care 1996, 19, 390-393. [CrossRef] [PubMed]

50. Sparks, J.D.; Sparks, C.E. Insulin regulation of triacylglycerol-rich lipoprotein synthesis and secretion. Biochim. Biophys. Acta 1994, 1215, 9-32. [CrossRef]

51. Folch, J.; Lees, M.; Sloane Stanley, G.H. A simple method for the isolation and purification of total lipides from animal tissues. J. Biol. Chem. 1957, 226, 497-509. [PubMed]

(C) 2017 by the authors. Licensee MDPI, Basel, Switzerland. This article is an open access article distributed under the terms and conditions of the Creative Commons Attribution (CC BY) license (http://creativecommons.org/licenses/by/4.0/). 